\title{
Cultura e Pandemia: precarização do trabalho cultural na Baixada Fluminense
}

DOI: https://doi.org/10.22409/pragmatizes.v11i21.48804

\author{
João Guerreiro ${ }^{1}$ \\ Bruno Borja ${ }^{2}$ \\ Luise Villares ${ }^{3}$ \\ Utanaan Reis Barbosa Filho ${ }^{4}$ \\ Bruno Duarte ${ }^{5}$
}

Resumo: A pandemia trouxe profundas alterações no campo da cultura. $O$ setor cultural enfrenta um enorme desafio com a necessidade de isolamento social, passando por um processo forçado de transição digital. O presente artigo busca compreender as consequências do neoliberalismo sobre as políticas culturais e o mercado de trabalho cultural, analisando a especificidade do impacto da pandemia na cultura da Baixada Fluminense,território periférico na Região Metropolitana do Rio de Janeiro, onde se evidencia o caráter informal e precário das condições de trabalho. Para interpretar o impacto da pandemia sobre a precarização do trabalho cultural, utilizamos dados primários extraídos da pesquisa Impactos da Covid-19 na Economia Criativa da Baixada Fluminense, desenvolvida pelo OBaC - Observatório Baixada Cultural.

Palavras-chave: trabalho cultural; precarização; pandemia; Baixada Fluminense; neoliberalismo.

\footnotetext{
1 João Luiz Guerreiro Mendes. Professor Instituto Federal do Rio de Janeiro (IFRJ). Pesquisador do Observatório Baixada Cultural $(\mathrm{OBaC})$. Doutor em Políticas Socioculturais (UFRJ), Brasil. E-mail: joao.mendes@ifrj.edu.br - https://orcid.org/0000-0003-1788-4132

${ }^{2}$ Bruno Nogueira Ferreira Borja. Professor da Universidade Federal Rural do Rio de Janeiro (UFRRJ). Pesquisador do Observatório Baixada Cultural (OBaC). Doutor em Economia (UFRJ), Brasil. E-mail: borja.bruno@gmail.com - http://orcid.org/0000-0002-4813-7001

${ }^{3}$ Luise Gonçalves Villares. Professora do Governo do Distrito Federal. Pesquisadora do Observatório Baixada Cultural (OBaC). Mestra em Patrimônio, Cultura e Sociedade (UFRRJ), Brasil. E-mail: villares.luise@gmail.com - https://orcid.org/0000-0002-8130-5134

${ }^{4}$ Utanaan Reis Barbosa Filho. Mestrando em Geografia pela Universidade Federal Rural do Rio de Janeiro (UFRRJ). Pesquisador do Observatório Baixada Cultural (OBaC), Brasil. E-mail: utanaan.reis@gmail.com - https://orcid.org/0000-0002-9690-8296

${ }^{5}$ Bruno Souza Duarte Lima. Mestrando em Economia Política pela Pontifícia Universidade Católica de São Paulo (PUC-SP). Pesquisador do Observatório Baixada Cultural (OBaC), Brasil. E-mail: lima.bsd@gmail.com - https://orcid.org/0000-0002-2753-434X
} 


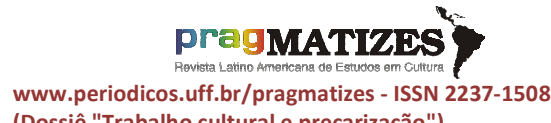

(Dossiê "Trabalho cultural e precarização")

\section{Cultura y pandemia: precarización del trabajo cultural en la Baixada Fluminense}

Resumen: La pandemia provocó cambios profundos en el campo de la cultura. El sector cultural se enfrenta a un gran desafío con la necesidad de aislamiento social, pasando por un proceso forzado de transición digital. Este artículo busca comprender las consecuencias del neoliberalismo sobre las políticas culturales y el mercado laboral cultural, analizando la especificidad del impacto de la pandemia en la cultura de la Baixada Fluminense, territorio periférico de la Región Metropolitana de Río de Janeiro, donde se evidencia el carácter informal y precario de las condiciones laborales. Para interpretar el impacto de la pandemia en la precarización del trabajo cultural, utilizamos datos primarios de la investigación Impactos del Covid-19 en la Economía Creativa de la Baixada Fluminense, desarrollada por $\mathrm{OBaC}$ - Observatório Baixada Cultural.

Palabras clave: trabajo cultural; precarización; pandemia; Baixada Fluminense; neoliberalismo.

\section{Culture and Pandemic: precarization of cultural labor in the Baixada Fluminense}

Abstract: The pandemic brought out profound changes in the field of culture. The cultural sector faces a huge challenge with the need for social isolation, going through a forced process of digital transition. This article seeks to understand the consequences of neoliberalism on cultural policies and the cultural labor market, analyzing the specificity of the impact of the pandemic on the culture of the Baixada Fluminense, peripheral territory in the Metropolitan Region of Rio de Janeiro, where the informal and precarious nature of working conditions is evidenced. To interpret the impact of the pandemic on the precarization of cultural labor, we used primary data from the research Impacts of Covid-19 on the Creative Economy of Baixada Fluminense, developed by OBaC - Observatório Baixada Cultural.

Keywords: cultural labor; precarization; pandemic; Baixada Fluminense; neoliberalism.

Cultura e Pandemia: precarização do trabalho cultural na Baixada Fluminense

Introdução

$O$ ano de 2020 foi marcado pela pandemia do coronavírus. Além dos efeitos sobre a saúde pública, a doença impactou, também, a economia mundial. A crise atual é particularmente crítica para o setor cultural devido à súbita e substancial perda de fontes de renda, decorrente do fechamento de teatros, museus, cinemas, centros culturais e cancelamento/adiamento de vários eventos públicos, apresentações e produções artísticas e culturais.

Já em abril de 2020, estudos do Centro de Desenvolvimento e Planejamento Regional da Universidade Federal de Minas Gerais (Cedeplar/UFMG) estimavam um impacto de $\mathrm{R} \$ 11$ bilhões na economia 
da cultura do país se houvesse três meses de paralização das atividades produtivas do setor (MACHADO et al., 2020). Nesse mesmo mês de abril, a Fundação Getúlio Vargas (FGV) estimou que a cadeia produtiva da cultura teria uma perda de receita de cerca de $\mathrm{R} \$ 46,5$ bilhões, projetando uma crise que perduraria, pelo menos, até o final de 2020 (CALDEIRA, 2020). Ambas as previsões já demonstravam a perspectiva de o impacto da crise sanitária ser de longo prazo na economia da cultura nacional.

De fato, a pandemia trouxe profundas alterações no campo da cultura, com 0 setor cultural enfrentando um enorme desafio pela necessidade de isolamento social. O cancelamento das atividades coletivas impôs um processo forçado de transição digital, com impacto desigual ao longo da cadeia produtiva da cultura. Isso significou uma alteração radical das condições de trabalho no setor, implicando uma tendência à precarização do trabalho cultural, agravada ainda mais pelas reformas neoliberais levadas a cabo nos últimos anos.

Neste artigo, buscamos compreender as especificidades do impacto da pandemia na cultura da Baixada Fluminense, território periférico dentro da Região Metropolitana do Rio de Janeiro, onde se evidencia o caráter informal e precário das condições de trabalho na cultura. Para tanto, serão utilizados dados da pesquisa Impactos da Covid19 na Economia Criativa, coordenada nacionalmente pelo Observatório da Economia Criativa da Bahia (OBECBA) ${ }^{6}$.

Enquanto colaboradores/as da pesquisa, atuando especificamente no território da Baixada Fluminense, apresentaremos alguns resultados que corroboram a hipótese da maior precarização do trabalho cultural na região durante a pandemia. Os dados apresentados compõem o relatório da pesquisa Impactos da Covid-19 na Economia Criativa da Baixada Fluminense, recém-publicado pelo $\mathrm{OBaC}$ - Observatório Baixada Cultural ${ }^{7}$.

\footnotetext{
${ }^{6}$ Participamos da pesquisa na condição de colaboração acadêmica, formando uma equipe com pesquisadores/as do Instituto Federal do Rio de Janeiro e da Universidade Federal Rural do Rio de Janeiro, para acompanhar os impactos da COVID-19 na economia criativa da Baixada Fluminense.

${ }^{7} \mathrm{O}$ relatório de pesquisa está disponível em: https://portal.ifrj.edu.br/sites/default/files/IFRJ/ ASCOM/obac_relatorio_final.pdf
} 


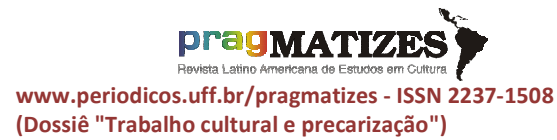

Dentre

os

elementos

analisados, destaca-se: o alto grau de informalidade do trabalho cultural, registrado já antes da pandemia; o baixo rendimento médio das/os trabalhadoras/es da cultura, mesmo com excessivas horas trabalhadas; 0 baixo grau de proteção social, especialmente quanto à contribuição para a previdência social; e a baixa capacidade para se manterem em tempos de suspensão/cancelamento das atividades culturais presenciais. Também se registra o alto impacto da pandemia nos salários, com as receitas diminuindo abruptamente. Dentre as estratégias adotadas para enfrentar a pandemia, destaca-se as modalidades que apontam para a necessidade de transição digital, embora isso não garanta rendimentos imediatos para a produção artística e cultural nos meios digitais, sinal de precarização do trabalho.

\section{Neoliberalismo, cultura e} pandemia

Desde 2014 vivemos um longo período de imobilismo econômico e impasse político por conta do projeto neoliberal em curso no Brasil. A hostilidade frente ao papel do Estado e em relação aos trabalhadores e trabalhadoras, mostrou o seu lado mais cruel a partir do golpe de 2016. A Constituição foi emendada com o objetivo de reformar o Estado e desmobilizar a classe trabalhadora, com mudanças que reforçaram a "vontade dos detentores da riqueza de liquidar com a cidadania social formalmente conquistada em 1988" (FAGNANI, 2017, p. 2) e ampliar a desvinculação dos recursos das políticas públicas.

Uma sequência de reformas neoliberais foi aprovada pelo legislativo: (i) a Emenda Constitucional 95, conhecida como Teto dos Gastos, aprovada em dezembro de 2016, que congelou os gastos primários por vinte anos; (ii) a Lei 13.467, aprovada em julho de 2017, que consolidou a reforma dos direitos trabalhistas e liberalizou amplamente o mercado de trabalho; e (iii) a Emenda Constitucional 103, aprovada em novembro de 2019, que promoveu a reforma da previdência.

O projeto neoliberal é extremamente agressivo e espoliativo com a classe trabalhadora. Apresentase como a mercantilização de todas as esferas da vida e o sucateamento do 
que é público, elementos centrais das políticas de austeridade que levaram ao aumento do desemprego e à diminuição da renda das famílias. Como afirmam Saad Filho e Morais (2020), o neoliberalismo tornou a classe trabalhadora brasileira cada vez mais heterogênea, com redução das oportunidades de emprego, desestabilização das garantias fundamentais, desvalorização dos salários e mudança na atuação do Estado. Assim, as relações de trabalho e as condições de vida da população estão sendo cada vez mais deterioradas.

No Brasil, a taxa de desocupação chegou a 14,6\% no terceiro trimestre de 2020 (IBGE, 2020a), sendo o maior percentual registrado na série histórica da PNAD Contínua desde 2012, e corresponde a 14,1 milhões de pessoas desempregadas. Temos 5,8 milhões de desalentados (IBGE, 2020c), que são as pessoas que desistiram de procurar trabalho por falta de oportunidades e, portanto, não aparecem nas estatísticas de desemprego. Além disso, a taxa de subutilização foi de $29,5 \%$ no último trimestre do ano e inclui uma grande parcela de jovens subcontratados e mal pagos. Já a taxa de informalidade foi de $38,8 \%$, o que equivale a 32,7 milhões de pessoas sem carteira assinada ou sem remuneração fixa (IBGE, 2020b).

A classe trabalhadora ampliada (formal e informal), com uma maioria de desempregados e subutilizados, se tornou peça de descarte no mercado de trabalho neoliberal. Entre as consequências sociais do neoliberalismo, temos a decomposição da classe trabalhadora, a diluição de sua cultura e de suas formas de vida, o que dificulta a organização social contra as medidas neoliberais.

No campo da cultura, o desmonte progressivo das políticas culturais virou um problema estrutural, que perdura há alguns anos. Desde a redução do orçamento federal da cultura a partir de 2014, passando pela tentativa do governo Temer de extinguir o Ministério da Cultura (MinC) em 2016 (barrada por um amplo movimento social), até o atual governo de tendências autoritárias que pôs fim ao MinC, reduzido a Secretaria Especial de Cultura, dentro do Ministério do Turismo. A política federal de cultura passou a refletir o 
caráter autoritário do atual governo, com intervenção direta no setor e direcionamento das políticas públicas a interesses particulares.

Apolítica neoliberal de ajuste fiscal e de teto dos gastos impôs às políticas culturais uma restrição enorme, inviabilizando sua atuação consistente de fomento. No entanto, a participação da despesa com cultura no total da despesa do governo federal foi de $0,07 \%$ em 2018, segundo o IBGE (2019). Ou seja, o impacto da redução orçamentária da cultura é ínfimo em termos de ajuste fiscal. Sua função é outra, marcadamente política e ideológica: desmantelar o setor e desarticular a luta dos trabalhadores e trabalhadoras da cultura, que resistem ao neoliberalismo e à precarização do trabalho cultural.

Vivemos hoje um enorme retrocesso, ou melhor, vivemos um momento de avanço do neoliberalismo, que, ao retirar recursos públicos da política cultural, relega seu devir aos desígnios da iniciativa privada. Assim, a própria redução do orçamento da cultura virou, em si, uma política cultural voltada para o mercado. Deixar as empresas decidirem os rumos da política cultural significa forçar uma concentração do financiamento e da produção nas mãos de artistas e produtores alinhados à política neoliberal, quebrando a resistência do movimento cultural.

A situação se agrava ainda mais ao constatarmos que o setor cultural foi um dos mais afetados pelas recentes alterações no mercado de trabalho, com aumentos significativos no grau de informalidade. Reféns das práticas neoliberais, trabalhadores/as da cultura foram empurrados no precipício do empreendedorismo. Transformados em Microempreendedores Individuais (MEI), tiveram sua condição de pessoa física transmutada em pessoa jurídica, num fenômeno conhecido como pejotização do mercado de trabalho: não são mais trabalhadores/as empregados/as, mas sim prestadores/as de serviço por conta própria.

Segundo dados da última publicação do Sistema de Informações e Indicadores Culturais do IBGE (2019), existiam no Brasil mais de 5,2 milhões de trabalhadores/as da cultura em 2018. Isso representava $5,7 \%$ do total de trabalhadores/as ocupados no 
GUERREIRO, João et al. Cultura e Pandemia: precarização do trabalho cultural na Baixada Fluminense. PragMATIZES - Revista Latino-

Americana de Estudos em Cultura, Niterói/RJ, Ano 11, n. 21, p. 95-124, set. 2021.

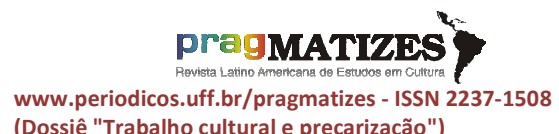

(Dossiê "Trabalho cultural e precarização") país. Entre 2014 e 2018, houve uma redução do percentual de trabalhadores/as com carteira assinada no setor cultural, passando de $45 \%$ para $34,6 \%$. Neste período também houve aumento de trabalhadores/as por conta própria no setor, passando de $32,5 \%$ para $44 \%$, com o grau de informalidade subindo de $38,3 \%$ para $45,2 \%$. Com isso, em 2018, eram 2,4 milhões de trabalhadores e trabalhadoras da cultura na informalidade e sem proteção social (IBGE, 2019).

A pandemia veio reforçar estas tendências, aprofundando suas contradições. Amplamente afetado, o setor cultural sofre com a impossibilidade de realizar sua potencialidade máxima: reunir e aglutinar pessoas, produzindo contatos culturais e gerando uma identidade comum. $\mathrm{O}$ alto contágio do vírus exigiu medidas de isolamento social $\mathrm{e}$ contenção das aglomerações. O setor foi um dos primeiros a parar e, provavelmente, será um dos últimos segmentos a retornar regularmente suas atividades presenciais.

Assim, a experiência estética presencial e coletiva de fruição da cultura foi comprometida e observou- se uma mudança significativa no campo, migrando rapidamente para os meios digitais, com 0 consumo individualizado dos produtos e serviços culturais. Neste contexto, as tendências de individualização e de digitalização do trabalho são rapidamente impulsionadas na pandemia, quebrando o cerne da perspectiva democrática e popular da cultura, restrita agora aos espaços privados.

A tendência à digitalização do trabalho, observada largamente na sociedade como um todo, tem um peso específico no setor cultural. Trabalhadoras/es da cultura estão sendo forçadas/os a migrar para os meios digitais, oferecendo produtos e serviços culturais na internet. A questão é complexa e envolve condições muito desiguais para a transição digital, especialmente se entendermos a dificuldade de transformar esse trabalho cultural digital em rendimentos concretos.

Está aí o segredo do fenômeno das lives durante a pandemia. Todos/as que tiveram seu trabalho cultural presencial inviabilizado pelo isolamento social se viram na necessidade de produzir conteúdo 


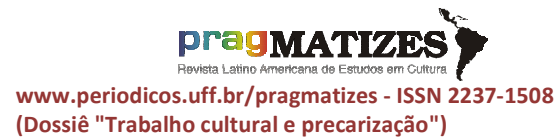

(Dossiê "Trabalho cultural e precarização") digital. Evidentemente, as condições de produção deste conteúdo são muito desiguais, atravessando desde cortes mais gerais entre indústria cultural $\mathrm{e}$ cultura popular, até cortes mais específicos de gênero, raça e classe. No entanto, a produção do conteúdo digital é só a primeira etapa da cadeia produtiva, depois é preciso distribuir este conteúdo e, por fim, realizar este produto ou serviço em dinheiro, obtendo uma renda.

O caso do segmento da música é emblemático, especialmente por se tratar de um dos segmentos mais estruturados do setor cultural brasileiro. Pesquisa da União Brasileira dos Compositores (UBC) e da Escola Superior de Propaganda e Marketing (ESPM) mostrou o impacto da pandemia nas condições de trabalho de artistas da música. A pesquisa indicou que $86 \%$ de respondentes tiveram sua renda com a música diminuída durante a pandemia, sendo que $30 \%$ afirmou ter perdido toda a renda proveniente da música. $\mathrm{O}$ perfil de respondentes expressa a característica de baixa renda dos trabalhadores e trabalhadoras da música, com $66 \%$ ganhando até 3 salários mínimos de renda individual mensal(UBC; ESPM, 2020).

A transição digital se apresenta de forma desigual dentre as trabalhadoras/es da música, apontando uma clara precarização do trabalho cultural neste segmento. Atualmente, o consumo de música via internet é uma tendência consolidada, aprofundada ainda mais na pandemia. No entanto, $59 \%$ de respondentes afirmaram não ter recebido nada em direitos autorais pagos por gravadoras, editoras ou agregadoras digitais durante a pandemia (UBC; ESPM, 2020).

As lives também expressam seu caráter desigual. Somente $13 \%$ de respondentes já faziam lives antes da pandemia, porém $43 \%$ afirmaram ter começado a fazer durante a pandemia. Assim, temos um total de $66 \%$ de respondentes executando lives, no entanto, $56 \%$ afirmaram não receber qualquer renda proveniente das apresentações ao vivo desde o começo da pandemia (UBC; ESPM, 2020). A partir dos dados apresentados, podemos inferir que houve uma grande precarização do trabalho cultural no segmento da música durante a pandemia, com 


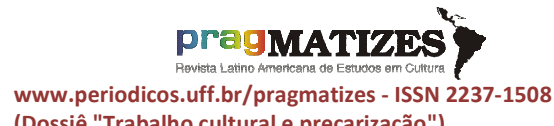

(Dossiê "Trabalho cultural e precarização") redução significativa dos ganhos de trabalhadoras/es da música no Brasil.

Para além disso, temos uma modificação profunda da cultura, não só em sua perspectiva mais específica da produção cultural, mas em uma perspectiva antropológica mais ampla, da cultura enquanto modo de vida. O isolamento social trouxe alterações radicais no modo de vida das pessoas, impactando seus afazeres cotidianos e suas necessidades vitais, como moradia, transporte, comunicação, lazer e, também, os processos de trabalho em todos os setores econômicos. Quem pode exercer o direito ao isolamento, sofre a imposição do trabalho remoto, tendo que transformar, repentinamente, o lar em espaço de trabalho e produção.

Refugiadas em casa, as pessoas descobriram 0 caráter essencial da produção cultural em suas vidas. Como manter a sanidade sem ouvir música? Como aproveitar um momento em família sem um filme? Como enfrentar a barbárie de centenas de mortes diárias sem um livro? Como viver sem dança, sem teatro, sem poesia? No entanto, esta centralidade da produção cultural na pandemia não foi valorizada pelo poder público. Trabalhadores e trabalhadoras da cultura enfrentam como podem a maior crise da história no setor cultural.

\section{Pandemia e trabalho cultural na} Baixada Fluminense

A chegada da Covid-19 no Brasil desnudou algo que muitos/as brasileiros/as vivenciam diariamente: as disparidades socioespaciais e econômicas. Todavia, isso não ficou claro logo de início. Com a promulgação do isolamento social no Rio de Janeiro, as primeiras informações que circulavam nos grandes meios de comunicação anunciavam que o vírus chegou ao Brasil através dos ricos; e, também, que tinha um caráter democrático. Ou seja, que ele não fazia escolha de suas vítimas, sendo visto como um fenômeno que atinge a todos/as da mesma forma, permitindo prevenção e tratamento igualitários. Deve-se dizer que esta análise não leva em consideração a realidade das periferias, das favelas e, particularmente, da Baixada Fluminense.

Pensar a Baixada Fluminense requer empreender um esforço de 
analisar algumas características que a difere das áreas centrais e nobres do estado. Destarte, o primeiro passo fundamental é avaliar sua sociabilidade, isto é, pensar o cotidiano, os fluxos, encontros, festas, resistência dos corpos, resolução de problemas, no tempo e no espaço; é entender a rua e o convívio como abrigo para além dos metros quadrados da casa (RAMOS, 2003).

A sociabilidade que se conserva nessa área difere bastante da sociabilidade dentro dos "enclaves fortificados" (CALDEIRA, 1997) presentes nas áreas nobres cariocas.Enquanto um grupo social pode se isolar dentro de casa e desfrutar dos equipamentos disponíveis no interior de condomínios fechados, os moradores da Baixada não possuem essa possibilidade, já que sua relação com a rua está ligada à condição de trabalhador/a periférico/a.

A noção de periferia, como pontuou Kowarick (1987), é caracterizada pelo espaço geográfico onde se sobressai um conjunto de carências ali observado e não encontrado em outro lugar: carência de serviços públicos, de equipamentos culturais, de urbanização, além de carências econômicas e de mercado de trabalho. A noção de cidadedormitório surgiu como síntese dessas carências e das grandes distâncias percorridas diariamente entre os locais de moradia e trabalho. Diferente das áreas nobres, a ocupação do território da Baixada Fluminense pela população pobre ocorreu sem apoio estatal. Logo, converteu-se em provedora de trabalhadores/as precarizados/as para a capital, intensificando a metropolização no estado (SOUZA, 2014).

Pelo caráter periférico do território, duas situações se colocam para o morador da Baixada Fluminense. Primeira, os trabalhadores que vão para a capital são os mais expostos ao risco de contaminação pela Covid-19, devido à circulação entre os municípios e à distância espacial entre moradia e trabalho ${ }^{8}$, aumentando o potencial da transmissão do vírus (RAMOS, 2020).

\footnotetext{
${ }^{8}$ Segundo o censo do IBGE de 2010, dentre todas as cidades do Brasil, Japeri é a que tem o maior índice de trabalhadores que levam mais de duas horas para chegar ao local de trabalho. Outros dois municípios da Baixada Fluminense encabeçam a lista de demora para chegar ao trabalho: Queimados ( $3^{a}$ posição) e Nova Iguaçu ( $4^{\mathrm{a}}$ posição).
} 
Segunda, os moradores da Baixada Fluminense que trabalham na própria região estão principalmente empregados em trabalhos informais, em condições precarizadas, circulando com suas mercadorias pelas ruas e transportes públicos, se expondo também ao vírus.

Desde os anos 1990 há uma tendência de destruição do modelo fordista-keynesiano no mundo do trabalho, substituído pelos distintos modos de terceirização, informalidade e precarização. Com isso, "a informalidade deixa de ser a exceção para tendencialmente tornar-se regra, e a precarização passa a ser o centro da dinâmica do capitalismo flexível" (ANTUNES; DRUCK, 2015, p. 21). Com a pandemia, houve aumento do desemprego e da informalidade, cujos impactos mais severos se dão em territórios periféricos, como a Baixada Fluminense.

Assim, a sociabilidade e a relação com a rua do povo da Baixada Fluminense são marcadas pela condição periférica do território. Os moradores, já imersos em uma pandemia de carências, com o coronavírus se encontram em uma encruzilhada: escolher entre trabalhar burlando $\mathrm{o}$ isolamento social $\mathrm{e}$ correndo o risco de se contaminar; ou não trabalhar e morrer de fome devido à falta de assistência do Estado.

Tudo isso reunido respalda a precarização da vida social do ser periférico. Essa "abrange a precariedade do direito, pois a maioria dos sujeitos não consegue ter acesso aos direitos que the foram garantidos constitucionalmente" (JORDÃO; STAMPA, 2015, p. 319). E isso vai além dos direitos trabalhistas, inclui direito aos serviços públicos, ao lazer e à cultura. Nesse sentido, é fundamental destacar a categoria de trabalhadores/as da cultura na Baixada Fluminense, analisando os efeitos da pandemia em suas atividades.

Durante os anos 1980 e 1990, a Baixada Fluminense vivenciou uma proliferação de instituições ligadas à cultura que, em sua maioria, possuíam relações com os movimentos sociais que floresciam na região. Nessa época, a cultura na Baixada era entendida como um meio para se atingir um fim, seja um ato político ou de resistência. Na década de 2010, sobressaiu-se na região o entendimento da cultura como um fim em si, deixando de ser um meio para 
alcançar outros objetivos, a cultura foi pensada como um produto (ENNE, 2012).

A lógica produtivista imposta através dos editais auxiliou nessa mudança de entendimento devido às exigências impostas, tais como metas e atividades obrigatórias a cumprir. Outro fator a ser mencionado sobre tais políticas de incentivo é que estas beneficiam apenas uma seleta parcela do setor cultural (grupos e artistas estruturados e consagrados), de forma a concentrar a geração de renda, o potencial econômico e as estratégias de marketing e captação de recursos. De acordo com Tommasi (2013), as regras dos editais constituem um verdadeiro filtro que pode impedir artistas que não são regularizados, ou não dominam as normas, de conseguirem financiamento.

Assim sendo, tal lógica contribui para a apropriação capitalista e a mercantilização da "cultura de periferia", isto é, da cultura produzida em áreas periféricas, porém moldada, industrializada e exportada para além de seu território. Por outro lado, com essa apropriação pelo mercado, a região periférica fica conhecida não apenas pelas costumeiras marginalidade e violência a ela associadas, mas também se agrega uma visão "positiva" de polo produtor de cultura.

Desse modo, 0 que se evidencia a partir da noção de periferia é que as tendências e problemas que atingem o setor em âmbito nacional chegam na Baixada Fluminense de forma potencializada, sem, no entanto, enfrentar formas institucionais de resistência. Porém, apesar da mercantilização e do distanciamento recente, o que se observa hoje é uma reaproximação entre produção cultural e movimentos sociais na Baixada Fluminense em tempos de pandemia.

\section{Precarização do trabalho cultural} na Baixada Fluminense

Em 14 de março de 2020, quando começou a proibição de funcionamento dos espaços culturais, shows, exposições, saraus, teatros e todas as demais atividades culturais, esse importante setor da economia, conforme demonstrado anteriormente, aponta para o colapso. É nesse contexto que o Observatório de Economia Criativa da Bahia (OBECBA) articulou, inicialmente, um grupo de pesquisadores da Universidade 


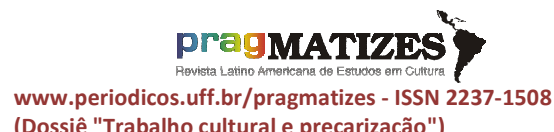

(Dossiê "Trabalho cultural e precarização")
Federal do Recôncavo da Bahia (UFRB), Universidade Federal da Bahia (UFBA) e Universidade Estadual da Bahia (UNEB), para realizar a pesquisa "Impactos da Covid -19 na Economia Criativa" na Bahia.

Segundo Canedo et al. (2020a), posteriormente, a equipe do OBEC-BA percebeu que $\mathrm{O}$ instrumento de pesquisa que estava sendo desenvolvido poderia ser replicado em outros estados da federação. Assim, buscaram ampliar o escopo e convidaram para integrar o grupo, pesquisadores/as da Universidade Federal do Rio Grande do Sul (UFRGS), Escola Superior de Propaganda e Marketing do Rio de Janeiro (ESPM/RJ), Instituto Federal do Rio de Janeiro (IFRJ) e Universidade Federal Rural do Rio de Janeiro (UFRRJ) ${ }^{9}$.

\subsection{Notas metodológicas da}

\section{pesquisa}

A equipe do OBEC-BA decidiu produzir dois instrumentos de coleta de dados: um direcionado aos

\footnotetext{
${ }^{9}$ Os/as autores/as do artigo participaram da fase de aplicação da pesquisa nacional e, após essa fase, se articularam em um grupo de pesquisa denominado $\mathrm{OBaC}-$

Observatório Baixada Cultural.
}

indivíduos (trabalhadores e trabalhadoras da cultura) e, outro, para as organizações, entendidas como coletivos culturais, produtoras culturais, grupos culturais e demais instituições formais ou informais que abarcam a Economia Criativa. O questionário foi dividido em três seções. Na primeira, o objetivo foi registrar o impacto da Covid-19 nas produções culturais, na renda do trabalho cultural e nas instituições relacionadas à cultura. $\mathrm{Na}$ segunda seção, buscou-se entender as estratégias utilizadas tanto por trabalhadoras/es da cultura, como pelas organizações para sobreviverem. Por fim, o OBEC-BA buscou entender a relação de indivíduos e organizações com os órgãos de financiamento público municipal, estadual e federal antes da pandemia (CANEDO et al., 2020a).

Ainda segundo Canedo et al. (2020a , p. 11), após a sua construção:

o questionário passou por duas fases de teste. $\mathrm{Na}$ primeira, foi enviado para pesquisadores e agentes culturais experientes que fizeram uma série de recomendações e sugestões. Posteriormente, entre os dias 27 de março e 17 de abril, foi disponibilizado para o público e 
recebeu respostas de 392 indivíduos e 255 organizações. A análise dos resultados dos primeiros 22 dias de aplicação contribuiu para a exclusão e a reformulação de algumas questões, de modo a facilitar a coleta e a leitura dos dados. O formato final do questionário de indivíduos possui 45 questões, sendo 32 questões obrigatórias e 13 opcionais, divididas em 30 fechadas e 15 questões abertas. Já o de organizações possui 37 questões, sendo 23 obrigatórias e 14 opcionais, divididas em 27 fechadas e 10 questões abertas. No total, a pesquisa ficou disponível entre os dias 27 de março e 23 de julho e recebeu 2.608 contribuições, sendo 1.639 respostas de indivíduos e 969 de organizações. A etapa seguinte foi dedicada ao processo de validação da base de dados. As respostas com campos completamente vazios e/ou sem informações centrais (estado e setor de atuação) foram excluídas.

Dado o momento pandêmico, não foi possível uma aplicação presencial do instrumento de coleta de dados. Assim, a ativação das redes institucionais e pessoais foram as principais formas do questionário chegar aos respondentes.

Assim, a partir do banco de dados primários cedido pelo OBEC$\mathrm{BA}$, nós, pesquisadores/as do $\mathrm{OBaC}$, realizamos um recorte selecionando apenas respondentes que se identificaram como moradoras/ES de algum dos treze municípios que compõem a região da Baixada Fluminense. Nosso objetivo foi produzir informações sobre a região, como possibilidade de comparar os impactos da Covid-19 no campo cultural em diferentes territórios do país. Em uma primeira análise, avaliamos as informações que serão apresentados a seguir.

Antes, porém, cabe informar que, na Baixada Fluminense, a pesquisa validou as respostas de 116 trabalhadores e trabalhadoras da cultura de quase todos os municípios da região, à exceção de Paracambi. Já em relação às organizações, obtivemos a validação de 39 questionários oriundos da Baixada Fluminense. Entretanto, ficamos sem a participação de organizações de quatro municípios, a saber: Guapimirim, Magé, Nilópolis e Paracambi.

3.2. Perfil das/ostrabalhadoras/es da cultura na Baixada Fluminense

De acordo com Anne (2013) e diversos outros autores ${ }^{10}$, o conceito

\footnotetext{
${ }^{10}$ Para as concepções simbólicas, culturais, políticas, econômicas e físicas sobre a
} 
"Baixada Fluminense" é uma expressão polissêmica e depende do interesse de quem está utilizando. Como pesquisadoras e pesquisadores que moram e/ou atuam na região, utilizaremos a mesma configuração territorial reconhecida pelo IBGE, facilitando as comparações com outras fontes de dados secundários e publicações oficiais. Nesse sentido, a Baixada Fluminense, conforme pode ser visto na Figura 1, é composta pelos municípios de Belford Roxo, Duque de Caxias, Guapimirim, Itaguaí, Japeri, Magé, Mesquita, Nova Iguaçu, Nilópolis, Paracambi, Queimados, São João de Meriti e Seropédica, todos inseridos na Região Metropolitana do Rio de Janeiro.
Baixada Fluminense ver OLIVEIRA (2004), TORRES (2006), entre outros.
Figura 1: Mapa da Baixada Fluminense

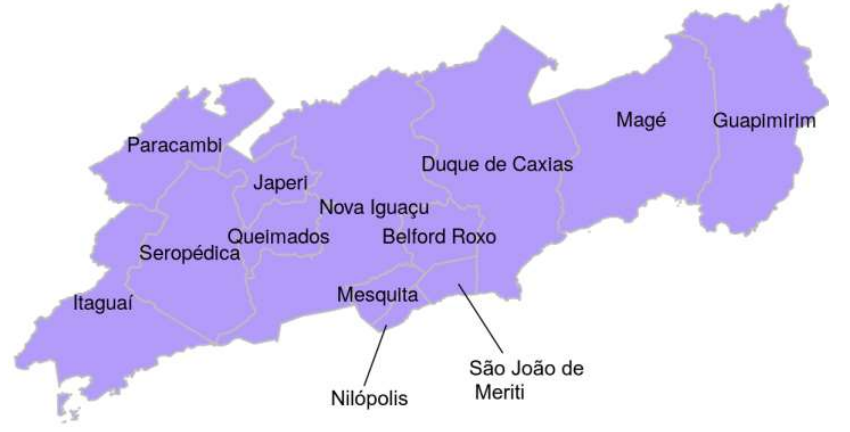

Fonte: elaboração própria ${ }^{11}$.

$\mathrm{Na}$ pesquisa nacional tivemos um total de 2.608 respostas, sendo 1.639 de trabalhadoras/es e 969 de organizações (CANEDO et al. 2020b), e, dessas, 1.910 foram validadas e analisadas. Fazendo um recorte em direção à Baixada Fluminense, a pesquisa validou os questionários de 116 trabalhadoras/es da cultura de quase todos os municípios região, à exceção de Paracambi. Já em relação às organizações, aqui entendidas como instituições formais e informais do setor cultural e grupos culturais, obtivemos a validação de 39 questionários oriundos da Baixada Fluminense. Entretanto, ficamos sem a participação de organizações de quatro municípios, a saber:

\footnotetext{
${ }^{11}$ Agradecemos a Igor Guimarães pela produção das figuras, gráficos e tabelas apresentadas nesse artigo, feitos a partir do banco de dados disponibilizado pela equipe do OBEC-BA.
} 
Guapimirim, Magé, Nilópolis e

pesquisa. O setor de atuação mais

Paracambi.

Avançando em busca de maior aproximação ao tema da precarização do trabalho cultural, analisamos os itens dos questionários referentes ao frequente entre trabalhadoras/es da cultura foi Música com 19,0\%. Entre as organizações/grupos culturais foi 0 setor de Produção Cultural com $20,5 \%$.

setor de atuação de respondentes da

Tabela 1: Principal setor de atuação - indivíduos e organizações (\%)

\begin{tabular}{|l|c|}
\hline Principais Setores & Ind. \\
\hline Música & 19,0 \\
\hline Cinema e Audiovisual & 14,6 \\
\hline Produção Cultural & 12,9 \\
\hline Teatro & 12,9 \\
\hline Artes Visuais & 8,6 \\
\hline Artesanato & 8,6 \\
\hline Dança & 4,3 \\
\hline Circo & 3,4 \\
\hline Livro, Leitura e Literatura & 3,4 \\
\hline Arte de Rua & 2,5 \\
\hline Artes Digitais & 1,7 \\
\hline Moda & 1,7 \\
\hline Cultura e Juventude & 0,9 \\
\hline Cultura LGBTQI+ & 0,9 \\
\hline Culturas Identitárias (outras) & 0,9 \\
\hline Design & 0,9 \\
\hline Festas e Celebrações & 0,9 \\
\hline Fotografia & 0,9 \\
\hline Patrimônio Imaterial & 0,9 \\
\hline Total & $\mathbf{1 0 0 , 0}$ \\
\hline
\end{tabular}

\begin{tabular}{|l|c|}
\hline Principais Setores & Org. \\
\hline Produção Cultural & 20,5 \\
\hline Livro, Leitura e Literatura & 15,4 \\
\hline Cultura Popular & 10,2 \\
\hline Música & 10,2 \\
\hline Dança & 7,7 \\
\hline Cultura de Matrizes Africanas & 5,1 \\
\hline Gestão Cultural & 5,1 \\
\hline Teatro & 5,1 \\
\hline Artes Visuais & 2,6 \\
\hline Cinema e Audiovisual & 2,6 \\
\hline Culturas e Infância & 2,6 \\
\hline Culturas e Juventude & 2,6 \\
\hline Culturas LGBTQI+ & 2,6 \\
\hline Formação e Mediação & 2,6 \\
\hline Moda & 2,6 \\
\hline Arte de Rua & 2,5 \\
\hline Total & $\mathbf{1 0 0 , 0}$ \\
\hline
\end{tabular}

Fonte: OBaC (2021). Elaboração própria.

Nesse ponto, cabe fazer um paralelo com o mapeamento dos grupos criativos da Baixada Fluminense realizado em 2015. Segundo o relatório final do Programa
Brasil Próximo (2015), nos 13 municípios da Baixada Fluminense a área musical também foi a primeira colocada. Uma das hipóteses para a crescente presença de grupos 
GUERREIRO, João et al. Cultura e Pandemia: precarização do trabalho cultural na Baixada Fluminense. PragMATIZES - Revista Latino-

Americana de Estudos em Cultura, Niterói/RJ, Ano 11, n. 21, p. 95-124, set. 2021.

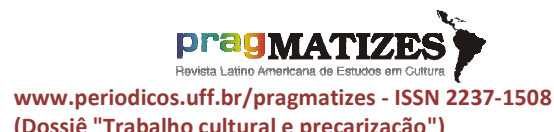

(Dossiê "Trabalho cultural e precarização") musicais nas áreas consideradas periféricas é a maior utilização dos recursos tecnológicos digitais para diferentes fins e propósitos. Na área musical, com softwares específicos para reprodução, gravação e criação de sons acessíveis ao público, hoje, diversos músicos conseguem gravar suas canções e disponibilizá-las através da internet em suas próprias casas.

Retornando à análise dos questionários, temos 0 setor de cinema e audiovisual como o segundo que mais absorve força de trabalho da cultura na Baixada Fluminense. Podemos utilizar a mesma hipótese sobre a democratização do acesso às tecnologias digitais para tentar nos aproximar dessa realidade.

Outro dado que chama atenção na Tabela 1 é o percentual tanto de trabalhadoras/es, como de organizações que atuam na Produção Cultural. Temos visto desde os Jogos Panamericanos de 2007 um aumento na demanda por força de trabalho especializada na área da produção cultural. Ao mesmo tempo, acompanhamos um aumento na demanda de produtores culturais em sistematizarem seus saberes junto ao ensino formal, desde a última década do século passado ${ }^{12}$. Seja pela necessidade, imposta pelas leis de incentivo fiscal, de apresentação de projetos culturais com orçamentos, cronogramas e prestação de contas, seja pela oferta no estado do Rio de Janeiro de três cursos superiores em Produção Cultural, percebemos que, mesmo com a crise econômica, ainda havia demanda por esse profissional no mercado de trabalho.

Ao analisarmos a remuneração média das/os trabalhadoras/es da cultura respondentes à pesquisa encontramos informações que corroboram o que nós, pesquisadores/as da Baixada Fluminense, vivenciamos no cotidiano de nossas atividades de pesquisa. Cerca de 95,0\% das/os trabalhadoras/es afirmaram receber até três salários mínimos, conforme o Gráfico 1. Para termos um parâmetro de comparação, nos dados agregados para o país, Canedo et al. (2020b) nos

\footnotetext{
${ }^{12}$ A Universidade Federal Fluminense e a Universidade Federal da Bahia criaram os primeiros cursos superiores de Produção Cultural do país na segunda metade da década de 1990, visando atender à demanda por profissionais da área, tanto no setor privado, como no setor público, principalmente no Ministério da Cultura e nas secretarias estaduais e municipais de cultura.
} 
apresentam que $71,3 \%$ de respondentes da Baixada Fluminense, respondentes estão nessa faixa de muito acima do dado nacional para renda. Já na faixa de renda até 1 essa faixa, que é de $31,2 \%$.

salário mínimo encontramos $63,8 \%$ de

Gráfico 1: Rendimento médio mensal- Baixada Fluminense (\%)

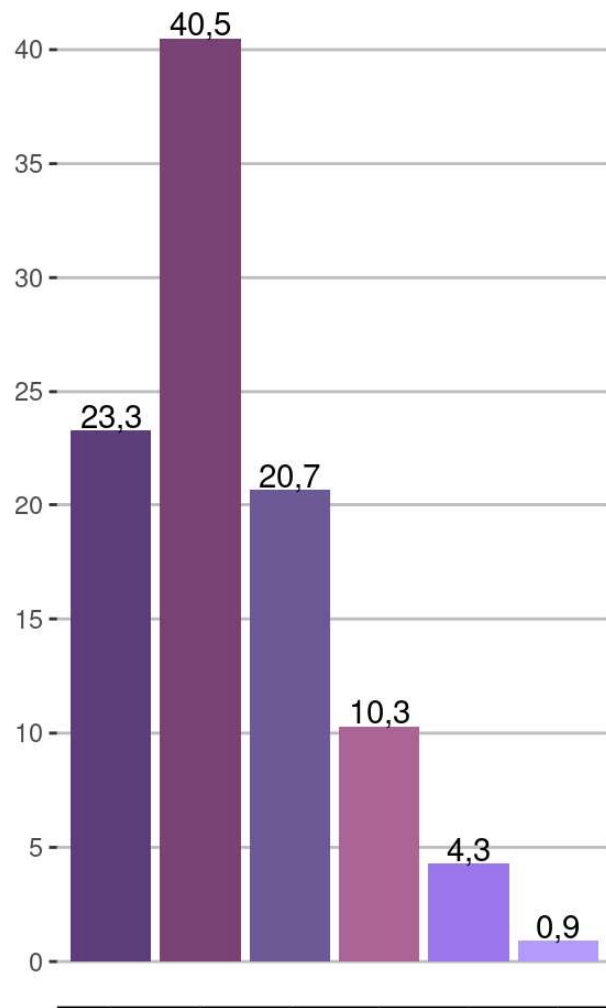

Até $\mathrm{R} \$ 522,50$

Entre $\mathrm{R} \$ 522,50$ e $\mathrm{R} \$ 1.045,00$ (1 $\mathrm{SM})$

Mais de $\mathrm{R} \$ 1.045,00$ a $\mathrm{R} \$ 2.090,00$ (2 SM)

Mais de $R \$ 2.090,00$ a $R \$ 3.135,00$ (3 SM)

Mais de $R \$ 3.135,00$ a $R \$ 5.225,00$ (5 SM)

Mais de $R \$ 5.225,00$ a $R \$ 10.450,00$ (10 SM)

Fonte: OBaC (2021). Elaboração própria.

Qualificando a informação sobre a remuneração média dessas/es trabalhadoras/es da Baixada, cabe ressaltar que $79,1 \%$ de respondentes tem o ensino superior completo ou em andamento. Ou seja, se trata de uma força de trabalho qualificada, porém com baixa remuneração, se comparada com as demais regiões do país. A baixa remuneração também não está relacionada ao tempo dedicado à atuação no campo da cultura, pois, segundo os dados obtidos nos questionários, $52,6 \%$ de respondentes informaram dedicar 40 horas ou mais por semana ao trabalho cultural de forma profissional. 
GUERREIRO, João et al. Cultura e Pandemia: precarização do trabalho cultural na Baixada Fluminense. PragMATIZES - Revista Latino-

Americana de Estudos em Cultura, Niterói/RJ, Ano 11, n. 21, p. 95-124, set. 2021.

Tabela 2: Quantidade de horas semanais dedicadas ao trabalho cultural- Baixada Fluminense

\begin{tabular}{|l|c|}
\hline $\begin{array}{l}\text { Quantidade de horas } \\
\text { semanais }\end{array}$ & $\%$ \\
\hline Até 14 horas & 12,9 \\
\hline 15 a 39 horas & 34,5 \\
\hline 40 a 44 horas & 22,4 \\
\hline 45 horas ou mais & 30,2 \\
\hline Total & 100,0 \\
\hline
\end{tabular}

Fonte: OBaC (2021). Elaboração própria.

Corroborando a hipótese de precarização do trabalho cultural na Baixada Fluminense, não causaram surpresa os resultados que obtivemos em relação à participação da renda proveniente da atividade cultural na renda total dessas/es trabalhadoras/es. Para $50,0 \%$ de respondentes da região, a atividade cultural representa menos ou até, no máximo, metade de sua remuneração, enquanto o restante provém de outras fontes. Apesar de despenderem muitas horas semanais na atividade cultural, essa acaba não sendo sua principal fonte de renda. $O$ que significa, por um lado, um total de horas trabalhadas semanalmente superior ao que deveria ser necessário para sua reprodução social, e, por outro lado, torna evidente o risco de afastamento permanente desses/as profissionais de suas atividades

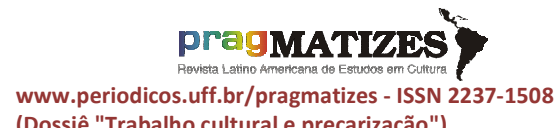

(Dossiê "Trabalho cultural e precarização")

culturais, caso os efeitos da crise sanitária se agravem.

Outra variável importante em relação ao processo de precarização do trabalho cultural na Baixada Fluminense é a chamada pejotização das trabalhadoras e trabalhadores da cultura. Isto evidencia como o trabalho cultural vem sendo destituído de direitos nessa época neoliberal. As instituições e organizações têm condicionado a contratação detrabalhadores/as culturais como MEls, transferindo, assim, parte do custo de produção para os/as trabalhadores/as, agora enquanto pessoas jurídicas. A situação se agravou ainda mais com as reformas trabalhistas realizadas no Governo Temer e com a alta taxa de desemprego registrada a partir de 2015. As opções de trabalhadores e trabalhadoras da cultura vêm diminuindo e crescendo o número de MEls, também na Baixada Fluminense, conforme podemos ver no Gráfico 2, a seguir: 
Gráfico 2: Tipo de Organização

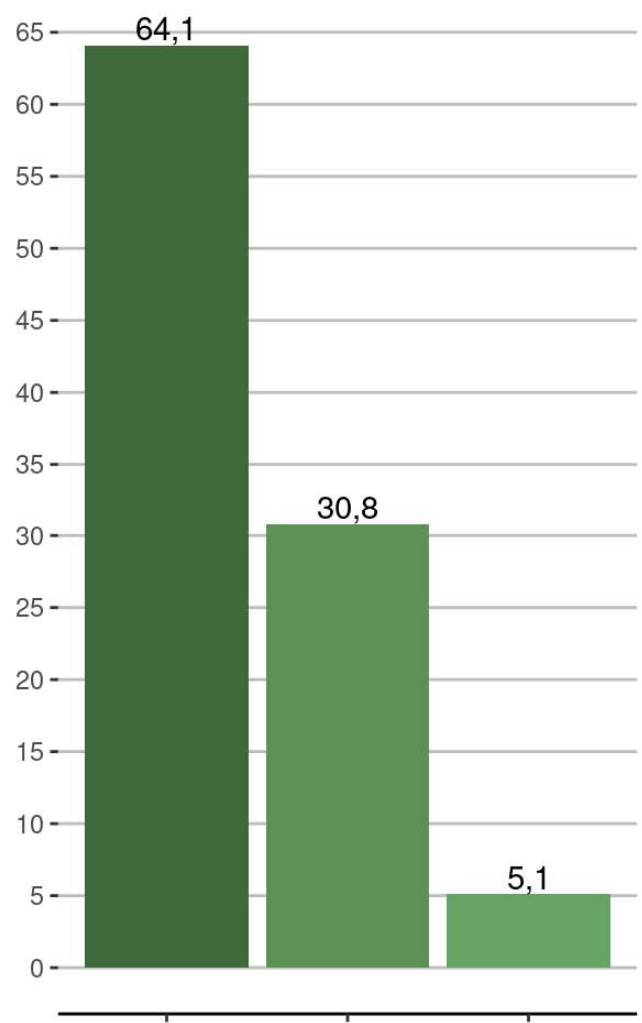

Associação sem fins lucrativos: $64,1 \%$

Microempreendedor Individual (MEI): 30,8\%

Fundação privada: $5,1 \%$

Fonte: OBaC (2021). Elaboração própria.

O número expressivo de organizações que se denominam Associações sem fins lucrativos, quando fazemos o recorte territorial da Baixada Fluminense, corrobora outras pesquisas anteriormente realizadas na região, onde se observou o elevado número de coletivos e grupos culturais (PROGRAMA BRASIL PRÓXIMO, 2015). Porém, chama a atenção que o segundo tipo de organização seja MEI $(30,8 \%)$. Nos dados nacionais, o percentual de organizações que se declarou MEI foi de $16,5 \%$, ou seja, a metade do registrado na Baixada Fluminense.

A formalização dos chamados empreendedores pode ser avaliada ao analisarmos sua cobertura previdenciária, ou seja, um índice de seu grau de proteção social. $\mathrm{Na}$ Baixada Fluminense, apenas 37,9\% responderam que contribuem para a previdência. É um dado preocupante, 
GUERREIRO, João et al. Cultura e Pandemia: precarização do trabalho cultural na Baixada Fluminense. PragMATIZES - Revista Latino-

Americana de Estudos em Cultura, Niterói/RJ, Ano 11, n. 21, p. 95-124, set. 2021.

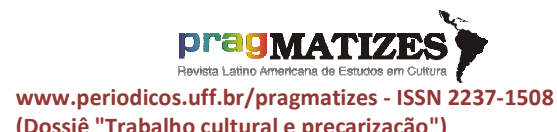

(Dossiê "Trabalho cultural e precarização") pois demostra a fragilidade da seguridade social na Baixada e fortalece a percepção de precarização do trabalho cultural na região.

Reforçando essa análise, apresentamos os dados da pesquisa referente à natureza da ocupação das/os trabalhadoras/es da cultura da Baixada Fluminense no período anterior à pandemia, isto é, até março de 2020. Pode-se observar, na Tabela 3 , que $64,7 \%$ de respondentes declaram trabalhar por conta própria, como autônomo ou freelancer, de forma individual, e $8,6 \%$ se declararam na mesma circunstância, porém empregando outros profissionais. Além disso, $8,6 \%$ eram empregados sem carteira assinada e $5,2 \%$ eram profissionais sem remuneração ou voluntários.

Tabela 3: Natureza da ocupação das/os trabalhadoras/es da cultura em marçoBaixada Fluminense

\begin{tabular}{|l|c|}
\hline Ocupação / março & $\%$ \\
\hline $\begin{array}{l}\text { Conta própria/autônomo/freelancer } \\
\text { (individual) }\end{array}$ & 64,7 \\
\hline $\begin{array}{l}\text { Conta própria/autônomo/freelancer } \\
\text { (empregando outros profissionais) }\end{array}$ & 8,6 \\
\hline Empregado sem carteira assinada & 8,6 \\
\hline $\begin{array}{l}\text { Serviço público (estatutária, } \\
\text { empregado público-CLT e militar) }\end{array}$ & 6,9 \\
\hline Empregado com carteira assinada & 6,0 \\
\hline $\begin{array}{l}\text { Profissional sem } \\
\text { remuneração/voluntário }\end{array}$ & 5,2 \\
\hline Total & 100,0 \\
\hline
\end{tabular}

Fonte: questionários da pesquisa Impactos da Covid-19 na Economia Criativa. Elaboração própria.

Podemos concluir, portanto, que $87,1 \%$ das/os trabalhadoras/es da cultura que responderam à pesquisa não possuíam vínculo empregatício formal antes da pandemia. Resultado um pouco acima dos dados da pesquisa nacional, que registra $80,7 \%$ sem vínculo formal (CANEDO et al., 2020b). Ambos expressam o alto grau de informalidade do trabalho cultural, índice importante de sua precarização. Vale destacar que esses dados estão muito acima dos $45,2 \%$ de informalidade registrados no setor cultural em 2018 (IBGE, 2019), indicando avanço da precarização do trabalho cultural, especialmente na Baixada Fluminense.

Nesse ponto, há duas hipóteses, que se completam, para o percentual tão elevado e díspar do apontado pelo IBGE. Conforme apresentando na seção 1 desse artigo, há um aumento da taxa de desemprego em 2020 em todo o país decorrente da crise econômica já em andamento e amplificada pelo impacto da Covid-19 nas atividades econômicas. $\mathrm{O}$ grupo de 
trabalhadoras/ES da cultura, provavelmente, foi o que mais teve necessidade de expressar suas opiniões sobre esse impacto quando a pesquisa foi divulgada a partir de março de 2020.

\subsection{Impactos da pandemia no} trabalho cultural da Baixada Fluminense

Com o campo da cultura mais fragilizado com a pandemia, procuramos analisar a percepção do impacto sobre o trabalho cultural. Ao longo do período de respostas do questionário, observamos uma modificação de percepção dos agentes culturais e criativos em relação as suas próprias atividades e quais consequências poderiam trazer. Assim, foi solicitado aos respondentes que informassem a perspectiva de adiamento ou cancelamento das atividades. Fazendo um recorte dos questionários respondidos por residentes na Baixada Fluminense, tivemos 96 respostas de trabalhadoras/es e 29 de organizações.
A seguir, podemos observar na Tabela 4 que, desse total, a maioria informou que teve entre $76 \%$ e $100 \%$ das atividades adiadas ou canceladas nos meses de abril, maio e junho. Quando perguntados sobre qual a previsão de adiamento ou cancelamento de atividades no segundo semestre de 2020, os percentuais caem abruptamente. Uma das explicações é que ao se ter maior informação sobre a pandemia e que a mesma só iria ser vencida com a produção e aplicação da vacina, novos contratos deixam de ser firmados. impacto, na realidade, é bem superior à percepção inicial, conforme pudemos observar diretamente nas atividades culturais no decorrer do ano de 2020. 
Tabela 4: Percentual de atividades adiadas, canceladas ou com previsão de cancelamento no $2^{\circ}$ semestre de 2020

\begin{tabular}{|c|c|c|c|c|c|c|}
\hline $\begin{array}{l}\text { Percentual de atividades } \\
\text { adiadas, canceladas ou } \\
\text { com previsão de } \\
\text { cancelamento }\end{array}$ & Tipo de respondente & $\begin{array}{c}\text { Março } \\
\%\end{array}$ & $\begin{array}{c}\text { Abril } \\
\%\end{array}$ & $\begin{array}{c}\text { Maio } \\
\%\end{array}$ & Junho \% & $\begin{array}{l}2^{\circ} \mathrm{Sem} . \\
\%\end{array}$ \\
\hline \multirow{2}{*}{ Até $25 \%$ das atividades } & Indivíduos & 17,7 & 5,2 & 3,1 & 1,0 & 2,1 \\
\hline & Organizações & 17,2 & 0,0 & 0,0 & 0,0 & 3,4 \\
\hline \multirow{2}{*}{$\begin{array}{l}\text { Entre } 26 \% \text { e } 50 \% \text { das } \\
\text { atividades }\end{array}$} & Indivíduos & 15,6 & 5,2 & 8,3 & 11,5 & 10,4 \\
\hline & Organizações & 6,9 & 6,9 & 3,4 & 6,9 & 3,5 \\
\hline \multirow{2}{*}{$\begin{array}{l}\text { Entre } 51 \% \text { e } 75 \% \text { das } \\
\text { atividades }\end{array}$} & Indivíduos & 8,3 & 11,5 & 11,5 & 10,4 & 8,3 \\
\hline & Organizações & 13,8 & 24,1 & 24,1 & 20,7 & 17,2 \\
\hline \multirow{2}{*}{$\begin{array}{l}\text { Entre } 76 \% \text { e } 100 \% \text { das } \\
\text { atividades }\end{array}$} & Indivíduos & 41,7 & 63,5 & 59,4 & 55,2 & 29,2 \\
\hline & Organizações & 55,2 & 65,5 & 69,0 & 69,0 & 31,0 \\
\hline \multirow{2}{*}{ Não se aplica } & Indivíduos & 2,1 & 1,0 & 1,1 & 2,1 & 4,2 \\
\hline & Organizações & 0,0 & 0,0 & 0,0 & 0,0 & 3,5 \\
\hline \multirow{2}{*}{ Não tenho como estimar } & Indivíduos & 7,3 & 11,5 & 13,5 & 14,6 & 40,6 \\
\hline & Organizações & 3,4 & 0,0 & 0,0 & 0,0 & 37,9 \\
\hline \multirow{2}{*}{ Nenhuma } & Indivíduos & 7,3 & 2,1 & 3,1 & 5,2 & 5,2 \\
\hline & Organizações & 3,5 & 3,5 & 3,5 & 3,4 & 3,5 \\
\hline
\end{tabular}

Fonte: OBaC (2021). Elaboração própria.

Ao mesmo tempo em que a pesquisa buscou aferir a expectativa de retorno às atividades presenciais, mediu, também, o tempo que as trabalhadoras e trabalhadores da cultura e as organizações avaliaram que conseguiriam sobreviver sem renda, dada a interrupção das atividades presenciais.

Segundo Canedo et al. (2020b), analisando os questionários de todas as regiões do país, as respostas apontaram que $71,2 \%$ das/os trabalhadoras/es e $77,8 \%$ das organizações teriam reservas financeiras para um período máximo de três meses sem os rendimentos provenientes da cultura.Tendo em vista a precarização já detectada nos itens relacionados ao rendimento médio das/os trabalhadoras/es, ao tempo dedicado à atividade cultural e ao grau de proteção social, nos debruçamos sobre os dados da Baixada Fluminense e obtivemos resultados que apontam um cenário até mais agudo para as trabalhadoras e trabalhadores da economia da cultura quando o assunto é reserva financeira para se manter em tempos de suspensão/cancelamento das atividades culturais.

Conforme apresentado no Gráfico 3, quase a metade $(46,9 \%)$ 
das/os trabalhadoras/es responderam ter recursos para menos de um mês de paralisação das atividades produtivas. Ampliando 0 cenário temporal de possibilidade de se manterem sem atividades produtivas para até três meses, cerca de $77 \%$ das/os trabalhadoras/es responderam ser este o prazo máximo para garantir sua sobrevivência. No caso das organizações criativas/culturais ao nível nacional, segundo Canedo et al. (2020b), 67,8\% informaram ter como se manterem durante até 3 meses sem atividades.

Ao analisarmos as organizações criativas/culturais na Baixada
Fluminense, obtivemos um percentual menor $(62,1 \%)$ afirmando ter reservas para esse mesmo horizonte temporal sem necessidade de outras formas de aporte financeiro. Apesar de menor em relação ao agregado nacional, o percentual ainda assim é muito elevado. Podemos supor pelos resultados obtidos que quem sobrevivia do trabalho cultural no primeiro semestre de 2020 apontava para a necessidade premente de uma política pública de renda emergencial para o setor.

Gráfico 3: Capacidade de trabalhadoras/es e organizações se manterem em caso de suspensão total de suas fontes de renda com cultura (\%)

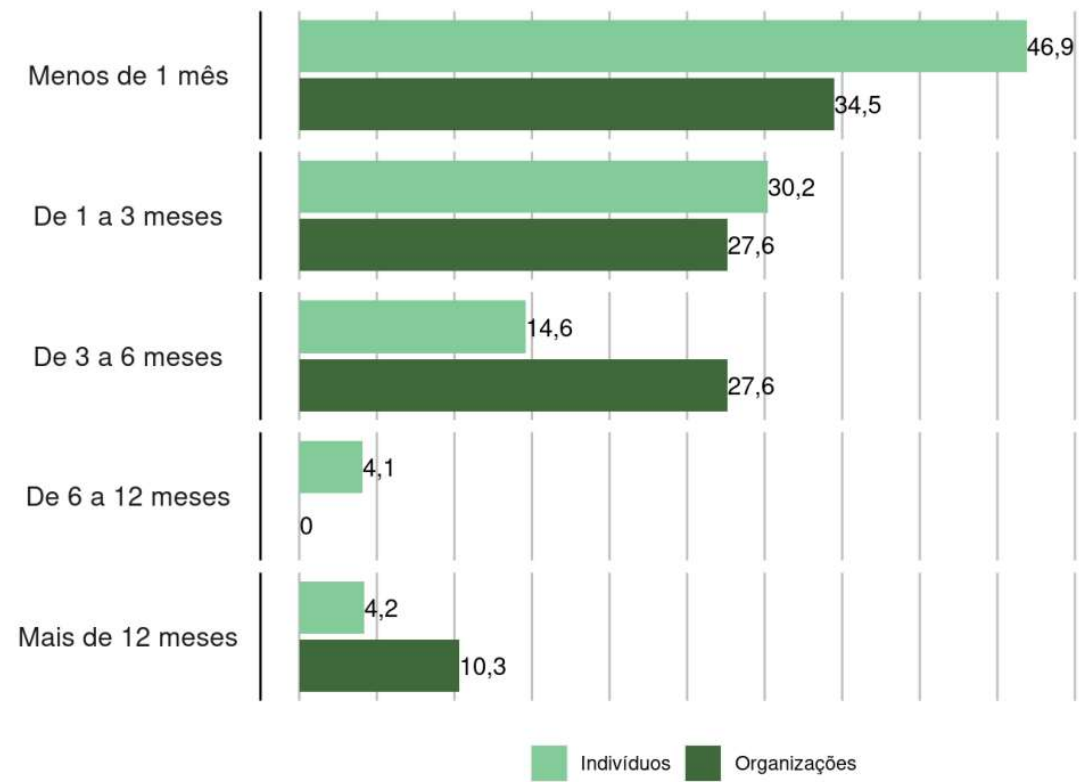

Fonte: OBaC (2021). Elaboração própria. 


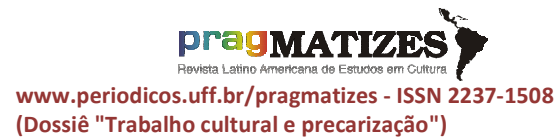

Como já apresentado, a presenciais em atividades remotas. Vários shows virtuais (as famosas lives) invadiram nossas casas e telas. Porém, essa é a verdade para um grupo muito pequeno de artistas, e as trabalhadoras e trabalhadores da cultura são mais do que isso. São iluminadoras, operadoras de som, camareiras, cozinheiras, produtoras culturais e uma série de profissionais que não tem como transformar seus fazeres em atividades remotas. Assim, analisando uma das perguntas do questionário do OBEC-BA, verificamos, na Tabela 5 , que $46,6 \%$ responderam estar desenvolvendo novos projetos/produtos, o que indica uma dificuldade dessas profissionais em reestruturarem sua produção/fazer cultural no curto prazo. impacto no salário, baixa proteção social, excessivas horas trabalhadas e, no contexto da pandemia, tendo essas horas diminuídas abruptamente, analisamos as questões referentes às táticas utilizadas pelas/os trabalhadoras/es da cultura em lidar com essa adversidade.

$\begin{array}{rrr}\text { É verdade que } & \text { parte dos/as } \\ \text { artistas conseguiram } & \text { rapidamente } \\ \text { transformar suas } & \text { atividades }\end{array}$


Tabela 5: Recursos utilizados para lidar com a pandemia

\begin{tabular}{|l|c|}
\hline \multicolumn{1}{|c|}{ Recursos } & $\%$ \\
\hline Desenvolvimento de novos projetos/produtos & 46,6 \\
\hline Revisão de despesas & 24,1 \\
\hline Investimento em divulgação e relacionamento com público & 23,3 \\
\hline Equipamentos para trabalho remoto & 22,4 \\
\hline Investimento em prestação de serviços/vendas online & 20,7 \\
\hline Serviços para trabalho remoto & 18,1 \\
\hline Negociação de novos prazos para projetos/serviços & 11,2 \\
\hline Treinamento/Capacitação & 11,2 \\
\hline Análise de mudança do modelo de negócio & 8,6 \\
\hline $\begin{array}{l}\text { Criação de novas formas de receita (ex: campanhas de } \\
\text { doação/crowdfunding/antecipação de venda de ingressos) }\end{array}$ & 7,8 \\
\hline Linha de crédito (empréstimos) & 2,6 \\
\hline $\begin{array}{l}\text { Estratégias digitais de relacionamento com público, venda de } \\
\text { produtos e prestação de serviços }\end{array}$ & 1,7 \\
\hline Outros & 11,2 \\
\hline
\end{tabular}

Fonte: OBaC (2021). Elaboração própria.

O segundo item citado pelos/as respondentes da Baixada Fluminense como tática de sobrevivência à crise é a revisão das despesas, com $24,1 \%$. Dado o menor rendimento médio dos/as participantes da pesquisa na Baixada Fluminense em relação ao agregado nacional, podemos supor que a redução de despesa não é uma opção, mas sim uma imposição para quem partia de um rendimento menor desde antes da pandemia.

Chamam atenção, ainda, as respostas em relação aos itens: equipamentos para trabalho remoto $(22,4 \%)$, investimento em prestação de serviços/vendas online $(20,7 \%)$ e serviços para trabalho remoto $(18,1 \%)$. Ao verificarmos os recursos apresentados pelas/os trabalhadoras/es da cultura na Tabela 5, podemos observar que esses quesitos são uma necessidade grande para a prestação de serviços da economia da cultura na Baixada Fluminense, questão central para viabilizar a digitalização do trabalho cultural no contexto da pandemia. ${ }^{13}$

\footnotetext{
${ }^{13}$ Cabe avaliar, também, como está o fornecimento dos serviços digitais frente à nova demanda provocada pelo isolamento social. Temos observado muitas críticas dos/as fazedores/as culturais da região sobre a qualidade do acesso à internet. Mas, como esse não foi um item abordado no questionário, será necessário incluir em um possível desdobramento da pesquisa.
} 
GUERREIRO, João et al. Cultura e Pandemia: precarização do trabalho cultural na Baixada Fluminense. PragMATIZES - Revista Latino-

Americana de Estudos em Cultura, Niterói/RJ, Ano 11, n. 21, p. 95-124, set. 2021.

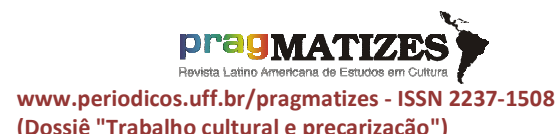

(Dossiê "Trabalho cultural e precarização")

\section{Considerações finais}

Nesse cenário pandêmico, o setor cultural está passando por um momento crítico de desestruturação e reestruturação, com acelerado processo de transição digital. $\mathrm{O}$ impacto desigual desta transição é evidente e, mais do que nunca, faz-se necessário elaborar políticas culturais que fomentem a produção independente e a cultural popular, no sentido de reduzir as desigualdades econômicas e sociais que atravessam a sociedade brasileira em geral, e o setor cultural em particular, especialmente em regiões periféricas como a Baixada Fluminense.

Desta forma, o artigo procurou evidenciar algumas das problemáticas do setor cultural durante a pandemia, especialmente a situação das/os trabalhadoras/es da cultura diante da paralisação das atividades presenciais. Observando a singularidade do momento histórico, buscamos apontar as consequências do avanço da agenda neoliberal na vida da classe trabalhadora e, através dos dados, analisar o trabalho cultural no território da Baixada Fluminense.

Os resultados obtidos pela pesquisa Impactos da Covid-19 na
Economia Criativa da Baixada Fluminense confirmam que houve aumento da precarização do trabalho cultural na região. O maior número de trabalhadoras/es que está sendo obrigado a tornar-se pessoa jurídica para acessar o mercado de trabalho, com alta informalidade e baixo nível de proteção social, associado a uma remuneração individual abaixo da média do mercado nacional, trazem preocupações adicionais ao trabalho cultural na Baixada Fluminense.

Particularmente crítica é a situação de trabalhadores/as da cultura para se manterem num contexto de pandemia e isolamento social, quando a suspensão de atividades presenciais significa uma redução drástica de rendimentos, apontando para a necessidade urgente de provisão de renda emergencial da cultura por parte do Estado. Mesmo se esforçando no sentido de traçar estratégias para realizar a transição digital, trabalhadores/as da cultura enfrentam uma grande dificuldade para reestabelecer seus rendimentos nos meios digitais. Tal fato aponta para um potencial aumento da precarização do trabalho cultural, na medida em que exige maior tempo de 
GUERREIRO, João et al. Cultura e Pandemia: precarização do trabalho cultural na Baixada Fluminense. PragMATIZES - Revista Latino-

Americana de Estudos em Cultura, Niterói/RJ, Ano 11, n. 21, p. 95-124, set. 2021.

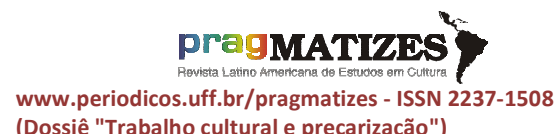

(Dossiê "Trabalho cultural e precarização") treinamento e trabalho, sem a garantia imediata de aumento da remuneração.

Os desafios frente a esse cenário, que já vinha se deteriorando com as políticas neoliberais, têm na pandemia um agravante, que vai exigir medidas compensatórias por parte do poder público e muita mobilização do campo cultural, como foi visto durante a elaboração e tramitação da Lei de Emergência Cultural, conhecida como Lei Aldir Blanc (LAB).Diante de todas as dificuldades para recebimento do Auxílio Emergencial da Cultura, a Baixada Fluminense vivenciou uma intensa e profícua mobilização para mapear artistas e coletivos. Criou-se uma rede de apoio para compartilhar dúvidas e saná-las, artistas e coletivos articularam-se para efetuar 0 cadastramento, enfrentando problemas de conexão de internet e falta de conhecimento das plataformas, montaram estratégias de atuação perante o poder público, reativaram fóruns e conselhos municipais e intensificaram a atuação nas redes sociais.

A Lei Aldir Blanc está em fase de execução, e, mais uma vez, a mobilização cultural será decisiva nesse ano de 2021. Com essa pesquisa e seus desdobramentos, $\mathrm{O}$ $\mathrm{OBaC}$ espera contribuir para a organização do movimento cultural na Baixada Fluminense,produzindo dados e análises sobre o setor, assim como contribuir para a elaboração de políticas culturais no território. A prorrogação da execução da LAB e sua futura institucionalização enquanto política cultural permanente fazem parte dessa luta coletiva, a qual nos somamos.

\section{Referências bibliográficas:}

ANTUNES, Ricardo; DRUCK, Graça. A terceirização sem limites: a precarização do trabalho como regra. O Social em Questão, Rio de Janeiro, ano 18, n. 34, p. 19-40, 2005.

CALDEIRA, João Bernardo. Com o coronavírus, cultura deve perder $\mathrm{R} \$$ 46,5 bilhões. Valor Econômico, 09/04/2020. Disponível em: https://valor.globo.com/eue/noticia/2020/04/09/com-ocoronavirus-cultura-deve-perder-r-465bilhoes.ghtml?fbclid=IwAR0nPNpdP6k TH7eVWxOFuau84VphZkwz8SxoWnl Tixy_XXzZiKEDcDBw8eQ. Acesso em: dez. 2020.

CALDEIRA, Teresa Pires do Rio. Enclaves Fortificados: a nova segregação urbana. Novos Estudos Cebrap, São Paulo, n. 47, 1997.

CANEDO, Daniele et al. A primeira a parar e a última a voltar? Pesquisando os impactos da COVID-19 na Economia Criativa - Um relato de 
GUERREIRO, João et al. Cultura e Pandemia: precarização do trabalho cultural na Baixada Fluminense. PragMATIZES - Revista Latino-

Americana de Estudos em Cultura, Niterói/RJ, Ano 11, n. 21, p. 95-124, set. 2021.

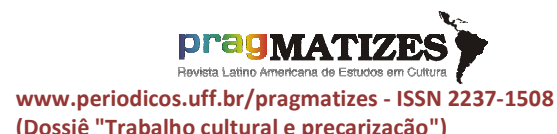

(Dossiê "Trabalho cultural e precarização") experiência. Boletim do Observatório da Diversidade Cultural, 2020a.

CANEDO, Daniele et al. Pesquisa Impactos da Covid-19 na Economia Criativa: relatório final de pesquisa 2020. Observatório da Economia Criativa da Bahia - OBEC-BA, 2020b.

ENNE, Ana Lucia. A "redescoberta" da Baixada Fluminense: reflexões sobre as construções narrativas midiáticas e as concepções acerca de um território físico e simbólico. PragMATIZESRevista Latino-Americana de Estudos em Cultura. Niterói/RJ, ano 3, n. 4, p. 6-27, mar 2013.

ENNE, Ana Lucia. Em "busca de dias melhores": cultura e política como práticas institucionais na Baixada Fluminense. Rumores, ed.12, ano 6, n. 2, p. 170-193, julho-dezembro, 2012

FAGNANI, Eduardo. O fim do breve ciclo da cidadania social no Brasil (1988-2015). Texto para Discussão. Campinas: Unicamp. Instituto de Economia, n 308 , jun. 2017.

GONCCALVES, Mariana Teixeira; SIMÕES, Janaína Machado. A dinâmica de participação social nos Conselhos Municipais de Cultura da Baixada Fluminense. Revista Pensamento Contemporâneo em Administração, v. 11 , n. 4, p. 56-71, 2017.

IBGE - Instituto Brasileiro de Geografia e Estatística. Censo Brasileiro 2010. Rio de Janeiro: IBGE, 2010.

IBGE. Desemprego chega a $14,6 \%$ no terceiro trimestre, com alta em 10 estados. Agência IBGE Notícias. 27 nov. 2020a. Disponível em: https://agenciadenoticias.ibge.gov.br/a gencia-noticias/2012-agencia-denoticias/noticias/29520-desemprego- chega-a-14-6-no-terceiro-trimestrecom-alta-em-10-estados Acesso em: 24 jan. 2021.

IBGE. Painel de Indicadores. 2020c. Disponível em: https://www.ibge.gov.br/indicadores Acesso em: 24 jan. 2021.

IBGE. PNAD Contínua: taxa de desocupação é de $14,3 \%$ e taxa de subutilização é de $29,5 \%$ no trimestre encerrado em outubro. Agência IBGE Notícias. 29 dez. 2020b. Disponível em:

https://agenciadenoticias.ibge.gov.br/a gencia-sala-de-imprensa/2013agencia-de-noticias/releases/29781pnad-continua-taxa-de-desocupacaoe-de-14-3-e-taxa-de-subutilizacao-ede-29-5-no-trimestre-encerrado-emoutubro Acesso em: 24 jan. 2021.

IBGE. Sistema de Informações e Indicadores Culturais 2007-2018. Rio de Janeiro: IBGE, 2019.

JORDÃO, Ana Paula Ferreira; STAMPA, Inez. Precarização no "mundo do trabalho": a experiência dos ambulantes dos trens da Região Metropolitana do Rio de Janeiro. O social em questão, Rio de Janeiro, ano 18, n. 34, 2015.

KOWARICK, Lúcio. A espoliação urbana. São Paulo, Paz e Terra, 1983.

MACHADO, Ana Flávia et al. Efeitos da Covid-19 na Economia da Cultura no Brasil.Nota Técnica, CEDEPLAR/UFMG, abril 2020. Disponível em: https://www.cedeplar.ufmg.br/noticias/ 1235-nota-tecnica-efeitos-da-covid-19na-economia-da-cultura-no-brasil.

$\mathrm{OBaC}$ - Observatório Baixada Cultural. Pesquisa impactos da Covid19 na economia criativa da Baixada Fluminense. GUERREIRO, João; 
BORJA, Bruno (coord.). Observatório Baixada Cultural, 2021. Disponível em: https://portal.ifrj.edu.br/sites/default/file s/IFRJ/ASCOM/obac_relatorio_final.pd f

OLIVEIRA. Rafael da Silva (org.). Baixada Fluminense: novos estudos e desafios. Rio de Janeiro: Paradigma. 2004.

PROGRAMA BRASIL PRÓXIMO. Mapeamento dos Grupos Criativos da Baixada Fluminense: Relatório Final. Rio de Janeiro, 2015.

RAMOS, Tatiana Tramontani. A geografia dos conflitos sociais da América Latina e Caribe. CLACSO, 2003. Disponível em: http://bibliotecavirtual.clacso.org.ar/ar/li bros/becas/2002/mov/tramon.pdf Acesso em: 29 ago. 2020.

RAMOS, Tatiana Tramontani. Pandemia é pandemia em qualquer lugar - vivendo a crise da Covid-19 de fora dos grandes centros. Espaço e Economia [Online], 18, 2020. Disponível em: http://journals.openedition.org/espacoe conomia/11406 Acesso em: 30 ago. 2020.

SAAD FILHO, Alfredo; MORAIS, Lecio. Brasil: neoliberalismo versus democracia. São Paulo: Boitempo, 2020.

SOUZA, Rodrigo Sampaio de. Sobre o poder na Baixada Fluminense: 0 exemplo do município de Nilópolis/RJ. Dissertação (Mestrado em Geografia) Pontifícia Universidade Católica do Rio de Janeiro, 2014.

TOMMASI, Lívia de. Culturas de periferia: entre o mercado, os dispositivos de gestão e o agir político. Revista Política \& Sociedade, Florianópolis, v. 12, n. 23, 2013.
TORRES, Gênesis (org.). Baixada Fluminense: a construção de uma história. Rio de Janeiro: IPAHB, 2004.

UBC - União Brasileira dos Compositores; ESPM - Escola Superior de Propaganda e Marketing. Músicos/as e pandemia. Relatório de pesquisa. Rio de Janeiro, 2020. 